\title{
What is it about intrauterine devices that women find unacceptable? Factors that make women non-users: a qualitative study
}

\author{
Claire Asker, Helen Stokes-Lampard, Jackie Beavan, Sue Wilson
}

\begin{abstract}
Introduction There is a lack of published research into the perceptions of 'non-users' of copper intrauterine contraceptive devices (IUDs). Despite this being one of the most commonly used methods of contraception in other countries, only $5 \%$ of contraceptive users in Great Britain aged 16-49 years currently use an IUD. This study explores how women's lay beliefs and perceptions about IUDs lead to rejection of this contraceptive choice.
\end{abstract}

Methods One-to-one semi-structured interviews were conducted with 10 women of varying ages and parity recruited from an urban general practice. None of the women had ever used IUDs but all had used contraception in the previous 6 months. Data were subjected to qualitative analysis.

Results Five analytical themes were identified: lack of objective information about IUDs, reported side effects of IUDs, anxieties about the process of fitting an IUD, IUDs as an infection risk and lack of personal control of an IUD, once fitted.

Conclusions Some of the themes identified mirrored those found in studies of user attitudes to and experiences of IUDs. Others, particularly the prominent worries about mess and embarrassment during fitting and the association between the hidden nature of the fitted device and unreliability, are new and need wider exploration.

J Fam Plann Reprod Health Care 2006; 32(2): 89-94 (Accepted 20 December 2005)

Key message points

- Women believed that intrauterine devices (IUDs) have to be fitted during menstruation.

- IUDs were felt to represent an infection risk unrelated to sexually transmitted infections.

- The hidden nature of a fitted IUD was associated with unreliability.

All Saints Medical Centre, Kings Heath, Birmingham, UK Claire Asker, MRCGP, FFFP, General Practitioner

Department of Primary Care and General Practice, The University of Birmingham, Birmingham, UK Helen Stokes-Lampard, MSc, MRCGP, Clinical Research Fellow and GP Principal

Sue Wilson, PhD, HonMFPH, Reader in Clinical Epidemiology

Division of Primary Care, University of Nottingham, Nottingham, UK

Jackie Beavan, BSc, MA, Senior Research Fellow

Correspondence to: Dr Helen Stokes-Lampard, Department of Primary Care and General Practice, Primary Care Clinical Sciences Building, The University of Birmingham, Edgbaston, Birmingham B15 2TT, UK. Tel: +44 (0) 1214142953.

Fax: +44 (0) 121414 6571. E-mail: h.j.stokeslampard@bham.ac.uk

\section{Introduction}

Following the publication of the National Institute of Clinical Excellence (NICE) Guideline on long-acting reversible contraception, women's choice regarding contraception has attracted media attention.1,2 Coppercontaining intrauterine contraceptive devices (IUDs) are the most widely used reversible method of contraception worldwide. It is estimated that 106 million women use IUDs, about $70 \%$ of whom are in China. ${ }^{3}$ However, in Great Britain the main methods of contraception are the contraceptive pill $(26 \%)$, sterilisation $(21 \%)$ and the male condom (19\%); IUDs are currently used by only $5 \%$ of contraceptive users. ${ }^{4}$ This level of use is lower than in other areas of Europe, particularly France and Scandinavia. ${ }^{5}$ Yet the clinical effectiveness of modern copper-containing IUDs is excellent, with a low failure rate of around $1 \% .^{6}$ Furthermore, insertion of a copper IUD, even up to 5 days after presumed ovulation, acts as very efficient emergency contraception. ${ }^{6}$

There are few studies that explore women's views or perceptions about contraception and even fewer that examine the way in which they perceive IUDs. There are, however, a number of studies that comment on the need for information regarding the factors that influence women's contraceptive choice. Lethbridge interviewed 30 American women from diverse ethnic and socioeconomic backgrounds about their lifetime experience with contraceptive use and concluded that research tended to focus on the effectiveness of methods rather than exploring women's perspectives of contraception. ${ }^{7}$ Belfield commented on the lack of published research in the UK about how different methods of contraception are perceived. ${ }^{8}$ Hunt and Annandale also referred to the paucity of literature relating to the perceptions of and attitudes to contraception. ${ }^{9}$ In 1994-1995, the Family Planning Association through the Contraceptive Education Service surveyed more than 700 women aged between 16 and 49 years to gain insight into how they chose their contraceptive method. They found that choice was highly individual and heavily influenced by a woman's personal circumstances and perceptions rather than by demographic characteristics such as age group, family size or social grade. The majority of women approaching a health professional had already decided on their preferred method of contraception before the consultation. ${ }^{10}$

The available literature suggests a number of factors that may be associated with a reluctance to use IUDs. These include: doubts about effectiveness, menstrual disturbances, pain, infection, expulsion of the device, ectopic pregnancy, infertility, cancer, and the unnaturalness of the device. ${ }^{11-16} \mathrm{~A}$ limitation of the available evidence is that women who have never used an IUD have not been considered as a discrete group, making it difficult to distinguish between the views of those who have stopped using IUDs and those who have never used one. Women who have tried and rejected the IUD as a contraceptive option can base their decision on personal experience, whereas those who have never used an IUD may base their decision making upon the negative experiences or perceptions of others. 


\section{ARTICLE}

The present research was motivated by the observation of women's reluctance to choose IUDs in one of the authors' (C.A.) practice. During discussions about contraceptive choice, women made comments such as "I do not really fancy one" or "They are not something I would really go for". When considering why women reject IUDs it was suspected that these vague comments concealed deeper concerns. Rivera and Best concluded that one way to overcome barriers to the use of IUDs was to focus more on the concerns of potential users and specifically listen to and address their 'myths and fears' surrounding IUDs. ${ }^{17}$

The main aim of the present study therefore was to explore the perceptions and lay beliefs about IUDs among women who had never used this method of contraception. Qualitative studies give insight into why people do what they do and explore phenomena from the individual's perspective. The objective of the study, therefore, was to enhance understanding of why women in the UK appear reluctant to consider IUDs as a contraceptive method.

\section{Methods}

\section{Ethical approval}

Ethical approval for the study was obtained from South Birmingham Local Research Ethics Committee in 2000. Women were given a letter of invitation to take part in the study together with an information sheet and offered an opportunity to discuss their involvement in the study. All participants provided informed, written consent to participate in the study and for the taping and transcribing of the interviews.

\section{Setting}

The setting was a general practice in an urban area of Birmingham, UK. The practice had a registered population of 4400 people with the majority being White British, and had postcode-based indicators of deprivation slightly below the national average.

\section{Recruitment and sampling}

Women were eligible to participate in the study if they had never used an IUD, if there were no restrictions on their use of an IUD (according to WHO criteria ${ }^{18}$ ), if they required contraception, and if they were able and willing to give informed consent. Women were excluded if they or their partners had been sterilised more than 6 months before the start of the study. Because IUDs have been promoted as an alternative to sterilisation, particularly for older women, it seemed reasonable to explore the attitudes to IUDs of women who had recently chosen sterilisation as their method of contraception. 19 The numbers of women excluded and the reasons for exclusion are summarised in Table 1.

Purposive recruitment of women who had never used an IUD was carried out within the practice, using two methods: (1) random selection from computerised records

Table 1 Reasons women were excluded from the study $(\mathrm{n}=40)$

\begin{tabular}{ll}
\hline Reason for exclusion & Women $(n)$ \\
\hline Self or partner sterilised more than 6 months ago & 11 \\
Current/past IUD user not identified by computer & 7 \\
Last natural period more than 2 years ago & 7 \\
Hysterectomy & 4 \\
Moved away & 4 \\
Severe learning difficulties & 4 \\
Infertility investigations in progress & 2 \\
No English spoken & 1
\end{tabular}

IUD, intrauterine device. and (2) opportunistic identification if receiving contraceptive services from the practice.

Practice computer records indicated that over $95 \%$ of the IUDs fitted at the practice over the previous 5 years involved women in the age range 25-54 years. A search of all women, registered at the practice, in this age group was conducted and women recorded as having previously used an IUD excluded. This resulted in the identification of 886 women from which a random $10 \%$ sample of 88 potential informants was generated. The medical records of these 88 women were searched to confirm 'never-user' status, and to confirm that no restrictions to use existed. 18 Seven were excluded as they had previously used an IUD, 11 women or their partners had been sterilised for more than 6 months, and 13 women were not in need of contraception. Some women were unable to give informed consent to the study, leaving a pool of 48 women.

Women were also opportunistically recruited by the researcher (C.A.) and other members of the practice clinical team if they had changed their contraceptive method within the previous 6 months.

Interviews were stopped when no new themes were emerging. Six women were recruited by random sampling (from 48) and four opportunistically, giving 10 participants in total.

\section{Data collection}

All interviews were conducted in the general practice in a small patient lounge on the upper floor, away from clinical areas. Women attended at a time convenient to them. One researcher (C.A.) undertook all the interviews, which were semi-structured in nature.

The interviews began with short, simple, biographical questions to help the participants feel at ease and to check respondents' understanding of the terms 'IUD' and 'intrauterine device'. These were followed by open-ended questions about participants' current and past methods of contraception; how they chose what method to use; sources of information; attitudes to and knowledge about IUDs; and their reasons for non-use.

The open-ended questions were followed by more focused questions on areas such as the side effects associated with IUD use. All participants were asked what, if anything, could be changed about an IUD to make it more acceptable. This last question aimed to explore the most significant reasons for non-use. Participants were free to introduce any issues they considered important and a conversational style was used throughout. Questions were not asked in a specific sequence, with the interview proceeding until all areas had been covered. All interviews were audio taped and fully transcribed. Notes were also taken during the interviews including observations of body language.

\section{Analysis}

Data collection and analysis were carried out in tandem by one researcher (C.A.). Transcripts were read repeatedly to get a feel for what each participant was saying and were then analysed manually line-by-line. Key words and ideas were identified and noted within the transcripts themselves.

Framework analysis was used to group similar ideas and develop analytical themes. ${ }^{20,21}$ The body language of several respondents was very striking at key points during interview and this contributed to the analysis.

\section{Study group characteristics}

Table 2 summarises the characteristics of the 10 study participants. 
Table 2 Characteristics of the study group participants $(\mathrm{n}=10)$

\begin{tabular}{ll}
\hline Characteristic & Findings \\
\hline Age range & $25-47$ (mean, 36) years \\
Current partner & Yes $=8$, No $=2$ \\
Parity & Never pregnant $=0$, currently pregnant $=2$, previously pregnant $=8$ \\
Current contraception & No $=4(2$ pregnant, 1 trying for pregnancy, 1 using no method), Yes $=6$ (condoms, female sterilisation, progestogen-only \\
& pill, Depo-Provera $\left.{ }^{\circledR}\right)$ \\
Ever considered using an IUD & Yes $=3$, No $=7$ \\
Employment status & Post office clerk, home care assistants (2), receptionist, nursery nurse, police officer, commercial artist, teacher, shop \\
& worker, unemployed \\
\hline
\end{tabular}

\section{Results}

Vague statements about not really liking an IUD were explored during the interviews. Although the main thrust of the research was to seek women's perceptions of IUDs, it became clear after the first few interviews that there was considerable variation in the quality of information that the respondents had about all aspects of IUDs. All participants were asked about the source of their information and they all cited both 'official' and 'unofficial' sources. 'Official' sources were leaflets, health care professionals (either community clinic or general practice-based), books and school. 'Unofficial' sources included personal narratives recounted by friends and relatives. Women showed considerable variation both in the quantity and accuracy of their information about IUDs. Women also used information they openly acknowledged to be potentially unreliable in order to support their decision not to use an IUD.

Anxieties about the fitting of an IUD were an area of particular concern among women recruited from the random cohort of non-users. Those agreeing to be interviewed from this group had strong feelings about this issue. Those recruited following a recent consultation for contraception had similar anxieties, but these were not as pronounced. Women from both groups indicated that the IUD was a method they would never consider.

The possibility of side effects of IUDs was cited by many women as a reason for non-use. This concern was similar to those of current and past users of IUDs in other studies, namely pain, bleeding disturbance, infection and doubts about method reliability. However, other themes emerged that were new. Some of these could also be considered as side effects of the method such as damage to a pregnancy in the event of method failure, but others were linked to the characteristics of an IUD itself. These were IUDs themselves as an infection risk and women's own lack of control of the method.

Five themes emerged from the analysis:

- Lack of objective information about IUDs

- Reported side effects of IUDs

- Anxieties related to the fitting of an IUD

- IUDs as an infection risk

- Lack of personal control of the method.

Letters of the alphabet have been used to identify respondents. Interviews from all 10 respondents contributed to the analysis.

\section{Lack of objective information about IUDs}

Women reported feeling ill informed about IUDs as contraception. Uncertainty about IUDs was enough to discourage women from using one.

"It's all hearsay and stuff like that. It's almost a taboo subject. I can't say anything constructive against it [IUD] because I've never had it. I have not got a clue, I'm totally naïve." [E]

Several participants felt ill informed because IUDs were not a method openly discussed; this and lack of published information were interpreted as meaning that 'official' providers of contraceptive information did not approve of IUDs. Women also relied on the original information they had been given about contraception, even if this had been many years previously.

"At school it was all AIDS and everything and condoms that were plugged. It [IUD] never came up in conversation." [B]

\section{Reported side effects of IUDs}

Women had inaccurate information about the side effects of IUDs. They had used 'official' sources of information such as leaflets, books, health care professionals and school, and 'unofficial' sources such as friends and relatives. The study confirmed the importance of the experiences and perceptions of friends and relatives as opposed to more 'official' sources of information. A number of the women reported that they had only heard bad reports about IUDs when they had been discussed.

"Um. My friend she had had one fitted and she was just in total agony for a week. I had a friend as well, it was a friend I work with, and she had a coil fitted and she had no problems, then she lost weight and then she became pregnant. And they told her it was because she'd lost weight." [H]

"You know you get these mother and toddler groups and you discuss this and that and it was all just bad publicity and that was another reason why I didn't ... um ... consider it. People said just don't go there." [C]

The fear of side effects from an IUD was a commonly cited reason for non-use.

"One of the main things that puts me off is just the fact that your periods are longer and could be heavier." [D]

Women reporting what they acknowledged to be unreliable information still seemed willing to use it to support their choice not to use an IUD. They talked about damage to a pregnancy should there be a failure of contraception with an IUD in place and used this as a reason for not using an IUD.I

"I've sort of heard the horror stories that people have actually got pregnant on them [IUD] and its been embedded in the embryo ... but I don't know how true that can be." [D]

"I've heard of people and they have had it come out stuck to the baby's head and things like that ... it really puts you off." [A]

"I have heard of things that if you do get pregnant horrible things like the coil wrapped around babies' necks and stuff like that." [E]

Women expressed concern that their partner might feel the device during sex.

"I've heard stories that men can feel it when you are having sex." [D] 


\section{ARTICLE}

Anxieties related to fitting of an IUD

Vague reasons for not really liking an IUD were explored during the interviews.

"I would instantly say no ... but I cannot really say why.” [E]

An important reason for not considering the method was the need for an IUD to be fitted. Women found it difficult to admit that this was their main reason for not considering an IUD. [Notes taken during the interviews recorded a repetitive pattern of gestures made by respondents at this point in the interview. Women fidgeted and wrinkled their noses and some even shuddered.]

"I don't want anyone messing about down there unless they really have to." [A]

Many of these concerns were related to other experiences of gynaecological examinations during the taking of cervical smears and childbirth.

"I do come and have a smear but I do not like it because it goes back to having my daughter because at the time it was so horrendous ... it brings it all back and I just, I just couldn't go like this." [J]

Anxieties related to the fitting of an IUD centred on the mess and embarrassment involved. Women who discussed their attitude to the fitting of an IUD all reported that it had to be fitted while they were having a period and they found this extremely off-putting.

"The thought that you have to have it put in place when you come on does not appeal to me at all. It's the mess factor." [D]

"I just find that embarrassing to be messed about when you are on anyway." [G]

The need for IUD fitting is not a feature of the method that can be changed and means that for many women the method may always be unacceptable.

"I don't think there's much you could change because you can't swallow it." [laughter] [A]

All the women were asked whether they would ever consider using an IUD for contraception. Seven women indicated that they would never consider it and three said that they might. It was not possible to distinguish the definite non-users from the possible users by their attitudes to fitting alone.

The preference for a female doctor was only mentioned spontaneously by two women.

"The thought of ... I mean you haven't got a choice if you can have a man or a lady it was just like you got whoever ....” $[\mathrm{H}]$

When asked about this, the remaining participants did not express a preference.

\section{IUDs as an infection risk}

Concern was expressed about IUDs as an infection risk for two reasons: first, the lack of any protection from sexually transmitted infections (STIs) if an IUD was used as the only contraceptive method and, second, the IUD itself was considered as unclean and unhygienic and consequently an infection risk.

Women identified that the IUD itself gave no protection against STIs, and that condoms were needed to provide such protection. These women were currently using or had in the past used condoms as their preferred method of contraception. Participants did not link acquired STIs to problems with infection from IUDs.

"Um. It's probably a good form of contraception if you are in my position now where I know my husband's sexual background. I think a condom is more appropriate if, you excuse me, you don't know where that other person has been." [B]

"Even if you've got one of those [IUD] in, your protection is only on the inside, you'd still need to use sort of a condom you know if it was someone fresh." [H]

An IUD was regarded as a 'foreign body' and unclean, unhygienic and consequently an infection risk, separate from concerns about STIs.

"No I don't like the thought of a foreign body inside you ... something that's accumulating bacteria." [C]

"I think it was just the thought that it was a piece of metal in you ... and it does sort of picture rust." [H]

\section{Lack of personal control of the IUD}

Women expressed a need to feel in personal control of their contraception. Because an IUD cannot be seen after it is inserted, they felt it would be unreliable and that they had no control over it. Out of sight was certainly not out of mind.

"The bottom line is that they can be unreliable and I would not want to consider anything that is the slightest bit unreliable. I think they'd be less reliable than a condom because with a condom you can actually see what's happening ... you feel as though you are in charge." [C]

"How can you be sure that everything is working fine?" [I]

Other issues linked to this theme were fears about IUDs getting lost inside a woman's body or somehow becoming dislodged during sex. Although women realised correctly that an IUD that became misplaced or expelled could not be relied upon, they still felt uncertain about IUD reliability even if they were sure it was still in place. String checking to determine if the device was still in place was not mentioned by any of the women.

An IUD needs to be fitted and removed by a professional. It was the need for removal by someone else that some participants felt constrained their control over their contraception.

"I think with the pill and with the condom you can choose to stop and use them ... the coil's there until you go to the doctors to get it taken out ... I mean if you choose to use the others then that's up to you." [I]

\section{Discussion}

The 1996 survey for the Contraceptive Education Service found low levels of information about contraception of all kinds. ${ }^{10}$ It is disappointing to see that the situation has not changed, with participants still feeling ill-informed about IUDs. The power of personal narratives is reflected in the fact that women appear to be more influenced by a friend having experienced a "terrible time" with an IUD than any number of statistics. Use by women of 'unofficial' sources of information was found in all the themes that emerged from data analysis. The importance of women's lay system of beliefs about contraception cannot be underestimated. ${ }^{22}$ It is easy to slip into the deficit model and assume that women are ignorant or irrational. However, understanding and analysis of 'lay' knowledge is as important as 'official' or 'expert' knowledge, ${ }^{23}$ particularly as many lay beliefs have a basis in medical paradigms. ${ }^{24}$

Women knowingly used information of doubtful quality to support their choice not to use an IUD. Belfield 
discussed apparent irrationality of choice in her review of consumer perceptions of family planning, highlighting the importance of the media in spreading misleading information and negative publicity about IUDs. ${ }^{8}$

The belief that an IUD must be fitted during menstruation was a highly significant barrier to considering the method among the women interviewed. Participants feared the mess involved, and their body language was very striking with outward expressions of disgust at points during the interviews when this issue was discussed. This is a new finding and may reflect the lack of research amongst non-users of the method. It is not clear from where this belief emanated. Current patient information leaflets explain that IUDs can be fitted during menstruation but also at other times during a woman's cycle. ${ }^{25,26}$

Recruiting from a computer-generated random list of women who were all non-users of IUDs seemed initially a good way to proceed. However, this recruitment strategy had its problems. Women recruited from this group all had very definite negative views about the fitting of an IUD. As a response to this, women were also recruited after a consultation for contraception. These women, too, had strong negative views about IUDs, although these were not so focused on fitting anxieties.

Respondents were concerned that a pregnancy resulting from IUD failure would be 'damaged'. It might be tempting to dismiss such concerns as far-fetched but they have reality for some women. ${ }^{27,28}$ However, a survey of 212 pregnancies that resulted after a failure of intrauterine contraception found no instances of congenital abnormality among the live births. ${ }^{29}$

A systematic review of IUDs and upper genital tract infection concluded that contemporary IUDs are much safer than previously thought. ${ }^{30}$ However, women interviewed believed that IUDs were an ongoing infection risk due to their status as a 'foreign body'. They worried that an IUD would accumulate secretions and bacteria during its lifespan and become more hazardous as a result. This is in direct contradiction to the recommendations of the World Health Organization study that IUDs should be left in place up to their maximum lifespan, because of the increased infection risk at the time of insertion. ${ }^{18}$ Some women did acknowledge that an IUD did not offer any protection against STIs, but did not connect infection risk with STIs and the insertion of the device.

IUDs are promoted as 'low-maintenance' contraception; however, this concept was not appealing to the non-users who participated in this study. Out of sight was not out of mind. The women's view that an IUD was invisible and out of their control, and therefore less reliable, is in direct contrast to professionals' views of the advantages of an IUD. ${ }^{31}$ This was a new and unexpected finding, although it is known that women tend to underestimate the reliability of modern IUDs. ${ }^{32}$ Women felt that the need for an IUD to be both fitted and removed by a health professional weakened their own control of their contraception.

\section{Limitations of the study}

The study included women from a wide age range and employment background. All the respondents were recruited from one general practice, were White British and currently either obtaining their contraception from their family doctor or buying condoms. Despite approaching a number of women from other ethnic groups, none of them were willing to take part in the study.

Although the researcher was careful to highlight the fact that non-participation would not prejudice clinical care, this might have been a consideration for some potential participants.
Participants knew that the subject of the research was the reasons behind their non-use of IUDs and therefore they had time to consider their responses. This is not the same situation as women seen in a clinical setting discussing their contraception.

All of the women in this sample had previously been pregnant. Women who have never been pregnant or never had to undergo pelvic examination may have different perceptions. Purposive sampling for nulliparous women should be done as a next step to further explore anxieties.

\section{Conclusions}

Existing research into women's ideas about IUDs as contraception has almost exclusively involved current and past users of IUDs and used questionnaires and surveys. This study is innovative, seeking the views of non-users using a qualitative methodology. The beliefs that IUDs must be fitted during menstruation and that infection risk increases with duration of use are contrary to current medical opinion. The link between unreliability and the hidden nature of the fitted device was a new and unexpected finding.

Because an IUD is a 'medical' contraceptive method requiring input from health professionals at fitting and removal, their influence on uptake is inevitably greater than with other methods. ${ }^{13}$

A balanced and informed approach is needed when counselling women who might consider an IUD to allay myths and unfounded fears. ${ }^{17}$ Evidence exists that many women are dissatisfied with the level of communication within family planning consultations. ${ }^{13}$ Misunderstandings arise when clinician and client each assume that the other shares their own understanding. Accessing women's lay beliefs has enhanced our understanding of why women discount an IUD as a contraceptive option. We suggest that the findings of this study could form the basis for changes to written educational materials about IUDs, for both clinicians and potential users. Information about participants' fears could be presented in such materials in tandem with objective information about IUDs. Inclusion of positive personal narratives may help to counteract the negative impact of 'unofficial' information sources.

In conclusion, the findings of this preliminary study contribute to our understanding of women's reluctance to consider what is a highly reliable but underused method of contraception in the UK.

Statements on funding and competing interests

Funding. Helen Stokes-Lampard was funded by a Department of Health Researcher Development Award. Sue Wilson was funded by a Department of Health Career Scientist Award.

Competing interests. None identified.

References

1 National Institute of Clinical Excellence (NICE). CG30 Long-acting Reversible Contraception: Full Guideline. http://www.nice.org.uk/ page.aspx?o=276710 [Accessed 7 November 2005]

2 Andalo D. A long shot. The Guardian, 2 November 2005.

3 Worldwide perspectives on IUD use. The Contraception Report (Vol. 9, Issue 4), September 1998. http://contraceptiononline.org/ contrareport/article01.cfm?art=54 [Accessed 2 May 2005].

4 Dawe F, Rainford L. Contraception and Sexual Health 2003. National Statistics, 2003. http://www.statistics.gov.uk/downloads/ theme health/contraception2003.pdf [Accessed 18 April 2005].

5 Population Reference Bureau. Reproductive Health Trends data. http://www.prb.org/PrintTemplate.cfm?Section=PRB\&template=/ ContentManagement/ContentDisplay.cfm\&contentID =5943 [Accessed 2 May 2005].

6 Faculty of Family Planning and Reproductive Health Care Clinical Effectiveness Unit. FFPRHC Guidance (January 2004). The copper intrauterine device as long-term contraception. J Fam Plann Reprod Health Care 2004; 30: 29-42.

7 Lethbridge D. Choosing and using contraception: towards a theory of women's contraceptive self-care. Nurs Res 1991; 40: 276-280. 
8 Belfield T. Contraception - consumer perspectives: past, present and future. Br J Fam Plann 2000; 26: 8-9.

9 Hunt K, Annandale E. Predicting contraceptive method usage among women in West Scotland. J Biosoc Sci 1990; 22: 405-421.

10 Walsh J, Lythgoe H, Peckham S. Contraceptive Choices. Supporting Effective Use of Methods. London, UK: Family Planning Association (Contraceptive Education Service), 1996.

11 Makkonen K, Hemminki E, Tuimala R. Pros and cons of intrauterine contraception - do perceptions of users and physicians differ? Scand J Prim Health Care 1994; 12: 190-196.

12 Sihvo S, Hemminki E, Kosunen E. Contraceptive health risks women's perceptions. J Psychosom Obstet Gynaecol 1998; 19: $117-125$.

13 Van Lunsen RHW, Arnolds HT, VanMaris M. Choices and changes in contraceptive behaviour: the role of information services. Patient Educ Couns 1994; 23: 197-202.

14 Oddens BJ, Visser AP, Vemer HM, Everaerd WT, Lehert P. Contraceptive use and attitudes in Great Britain. Contraception 1994; 49: $73-86$.

15 Colli E, Tong D, Penhallegon R, Parazzini F. Reasons for contraceptive discontinuation in women 20-39 years old in New Zealand. Contraception 1999; 59: 227-231.

16 Morehead JE. Intrauterine device retention: a study of selected psychosocial aspects. Am J Public Health 1975; 65: 720-730.

17 Rivera R, Best K. Consensus statement on intrauterine contraception. Contraception 2002; 65: 385-388.

18 World Health Organization (WHO). Medical Eligibility Criteria for Contraceptive Use. Geneva, Switzerland: WHO, 2004.

19 Royal College of Obstetricians and Gynaecologists (RCOG). Male and Female Sterilisation (Evidence-Based Clinical Guidelines No. 4). London, UK: RCOG Press, 2004. http://www.rcog.org.uk/ resources/Public/pdf/Sterilisation_full.pdf [Accessed 10 October 2005].
20 Clifford C (ed.). Qualitative Research Methodology in Nursing and Healthcare. Edinburgh, UK: Churchill Livingstone/Open Learning Foundation, 1997; 65-75.

21 Gantley M. A beginner's guide to developing a thematic analysis. In: Gantley M, Harding G, Kumar S, et al. (eds). An Introduction to Qualitative Methods for Health Professionals (Master Classes in Primary Care Research, No. 1). London, UK: Royal College of General Practitioners, 1999.

22 Anderson P (ed.). Oualitative Research: A Vital Resource for Ethical Healthcare. Proceedings of the conference organised by the UK Forum for Health Care, Law and Ethics and sponsored by the Wellcome Trust Biomedical Ethics Programme, London, UK, 1999.

23 Helman CG. Culture, Health and Illness. An Introduction for Health Professionals (2nd edn). London, UK: Wright, 1990; 86-127.

4 Shaw I. How lay are lay beliefs? Health 2002; 6: 287-299.

25 Your Guide to the IUD. IUD 02/00. London, UK: Family Planning Association (Contraceptive Education Service).

26 Prodigy Guidance - IUDs. http://www.prodigy.nhs.uk/clinical guidance/releasedguidance/webBrowser/pils/PL103.htm [Accessed 7 November 2005]

27 Cottingham J. Beyond acceptability: users' perspectives on contraception. Reprod Health Matters 1997; 5 (Suppl.): 1-4.

28 Zeidenstein G. The user perspective: an evolutionary step in contraceptive service programs. Stud Fam Plann 1980; 11: 24-29.

29 UK Family Planning Research Network. Pregnancy outcome associated with the use of IUDs. Br J Fam Plann 1989; 15: 7-10.

30 Grimes DA. Intrauterine device and upper genital tract infection. Lancet 2000; 356: 1013-1019.

31 Guillebaud J. Intrauterine contraception - what now and what next? Eur J Contracept Reprod Health Care 2001; 6: 11-14

32 Edwards JE, Oldman A, Smith L, McQuay HJ, Moore RA. Women's knowledge of, and attitudes to, contraceptive effectiveness and adverse health events. Br J Fam Plann 2000; 26: 73-80.

\section{Are you interested in getting more involved with the Journal of Family Planning and Reproductive Health Care?}

The Journal is seeking to recruit additional peer reviewers and book reviewers to assist the Journal editorial team. See below for further details of what is involved with these roles.

\section{Peer Reviewers}

If you have a special interest in one or more of the topics covered by the Journal and have some time available to peer review occasional papers in your own area(s) of expertise then perhaps you might be interested in joining the Journal's team of peer reviewers? In common with the majority of other academic journals, peer reviewers offer their services on a voluntary basis. However, if you are a member of the Faculty of Family Planning and Reproductive Health Care then each competed review counts for two (2) continuing medical education (CME) points.

For further information please contact the Editor or e-mail the Journal Editorial Office at journal@ffprhc.org.uk.

\section{Book Reviewers}

The Journal regularly receives books for review and for this it relies on the services of a small team of expert reviewers. Whilst no payment is offered in respect of this role, reviewers do get to keep the books they review thus offering an opportunity to build up the reviewer's own or their departmental book collection.

For further information please contact the Journal's Book Review Editor, Dr Kate Weaver, via e-mail (kate.weaver@lpct.scot.nhs.uk). Please provide your contact details (mail and e-mail addresses), together with a note of any special interests and/or expertise. 